\title{
Optimal generation and transmission development of the North Sea region: impact of
} grid architecture and planning horizon

Gea-Bermudez, Juan; Pade, Lise-Lotte; Koivisto, Matti Juhani; Ravn, Hans V.

Published in:

Energy

Link to article, DOI:

10.1016/j.energy.2019.116512

Publication date:

2020

Document Version

Peer reviewed version

Link back to DTU Orbit

Citation (APA):

Gea-Bermudez, J., Pade, L-L., Koivisto, M. J., \& Ravn, H. V. (2020). Optimal generation and transmission development of the North Sea region: impact of grid architecture and planning horizon. Energy, 191, [116512]. https://doi.org/10.1016/j.energy.2019.116512

\section{General rights}

Copyright and moral rights for the publications made accessible in the public portal are retained by the authors and/or other copyright owners and it is a condition of accessing publications that users recognise and abide by the legal requirements associated with these rights.

- Users may download and print one copy of any publication from the public portal for the purpose of private study or research.

- You may not further distribute the material or use it for any profit-making activity or commercial gain

- You may freely distribute the URL identifying the publication in the public portal 


\title{
Optimal generation and transmission development of the North Sea region: impact of grid architecture and planning horizon
}

\author{
Juan Gea-Bermúdez ${ }^{1,2, *}$, Lise-Lotte Pade ${ }^{1}$, Matti Juhani Koivisto², Hans Ravn ${ }^{3}$ \\ ${ }^{1}$ EER group, Department of Management, Technical University of Denmark, Building 426, Produktionstorvet, 2800, Kgs. Lyngby, \\ Denmark \\ ${ }^{2}$ Department of Wind Energy, Technical University of Denmark, Ris $\varnothing$ Campus, Frederiksborgvej 399, 4000 Roskilde, Denmark \\ ${ }^{3}$ RAM-løse \\ jigeab@dtu.dk
}

\begin{abstract}
The European Union is pushing to achieve a sustainable, competitive and secure energy supply in Europe. This has translated into significant long-term renewable energy targets towards 2050, and the ambition to improve the European grid. A large share of this development is expected to occur in the North Sea. This paper investigates which transmission architecture is the most beneficial to integrate large shares of renewable energy in the North Sea region, and the consequences of the planning horizon when planning such a system towards 2050 are analysed. This is achieved by performing investment optimization of generation and transmission for different scenarios. It is found that: 1) an integrated offshore grid configuration planned over a long planning horizon leads to cost minimization; 2) the grid topology is not likely to influence the penetration of variable renewable energy, but it will affect the contribution of each variable renewable energy type and the system costs; and 3) not taking the future into account when developing the energy system is likely to lead to a more expensive system. These results remark the importance of long-term planning horizon for energy systems and grid expansion and calls for a political focus on planning and international cooperation.
\end{abstract}

Key words — Grid, Offshore, Modelling, North Sea, Optimisation, Planning.

Nomenclature:

$\begin{array}{llllll}\text { VRE } & \text { Variable Renewable Energy } & \text { DK } & \text { Denmark } & \text { R } & \text { Region set } \\ \text { HVDC } & \text { High Voltage Direct Current } & \text { GB } & \text { Great Britain } & \text { T } & \text { Time step set } \\ \text { MILP } & \text { Mixed Integer Linear Programming } & \text { NL } & \text { Netherlands } & \mathbf{X} & \text { Transmission capacity } \\ \text { HVAC } & \text { High Voltage Alternate Current } & \text { BE } & \text { Belgium } & \text { K } & \text { Generation capacity } \\ \text { PDF } & \text { Probability Distribution Function } & \text { H2H } & \text { Hub to Hub } & \text { W } & \text { Weight } \\ \text { O\&M } & \text { Operation and maintenance } & \text { H2C } & \text { Hub to Country } & \mathbf{y} & \text { Time series } \\ \text { WRF } & \text { Weather Research and Forecasting } & \text { C2C } & \text { Country to country } & \text { F } & \text { Cumulative Distribution Function } \\ \text { CDF } & \text { Cumulative Distribution Function } & \text { DR } & \text { Discount Rate } & \text { L } & \text { Lifetime } \\ \text { OWPP } & \text { Offshore Wind Power Plant } & \text { DF } & \text { Discount Factor } & \text { B } & \text { Branch } \\ \text { SOS } & \text { Special Ordered Sets } & \text { C } & \text { Cost } & \text { N } & \text { Node } \\ \text { CF } & \text { Capacity factor } & \text { Y } & \text { Year set } & \text { O } & \text { Additional cost of offshore node } \\ \text { EU } & \text { European Union } & \text { A } & \text { Area set } & \text { p } & \text { Power-dependent } \\ \text { NO } & \text { Norway } & \text { G } & \text { Generator set } & \text { lp } & \text { Length- and power-dependent }\end{array}$

\section{INTRODUCTION}

\subsection{Motivation}

The objective of the European Union's (EU) energy policy is to assure an energy supply throughout Europe, which is sustainable, competitive and provides a high level of security of supply [1]. This has translated into ambitious long-term renewable energy targets in the EU for 2030 and 2050, and an ambition to improve the European energy grid. Furthermore, because of the substantial offshore wind potential in the North Sea region, a considerable share of the renewable energy is expected to take place there, which implies that the 
North Sea transmission grid has to be developed in the near future. This context opens the following questions. Which transmission architecture is the most beneficial to integrate large shares of variable renewable energy in the North Sea region: using traditional radial connections or going for a more complex offshore grid? In addition, what are the consequences of planning horizon when building such a system looking towards 2050: is it more likely to achieve a suboptimal system if the planning horizon is too short?

In energy system planning, considering coordination and integration can be very important, especially regarding investments [2]. In [3], a theoretical model for trade in electricity is presented, and the authors show that removing barriers to trade by e.g. increasing the interconnectivity between regions increases the efficiency of the market and therefore overall welfare. In [4] it is found that the benefits of integrating European electricity markets could be $3.4 \mathrm{~b} €$ per year. Benefits from market integration in Europe are also found in [5], where the authors analyse how different power market aspects of the different countries impact welfare and generation adequacy.

Recently, interest in grid expansion in the North Sea region has gained more attention, and the development of the North Sea offshore grid is highly prioritised by the European Commission [6]. Several studies indicate that a North Sea offshore grid can contribute to reductions in investment costs [7] as well as operational costs [8]. Additionally, in [9], a number of cases were analysed based on a system modelling approach finding that a meshed offshore grid solution is the most beneficial. With a larger focus on policy implications, similar results were obtained in [10].

The purpose of this paper is to analyse the extent to which the development of a complex offshore grid is beneficial compared to using traditional radial connections, and to study the effects of having a short or long planning horizon.

\subsection{Contribution to literature}

This paper contributes to the existing literature by 1) performing an intertemporal optimization of the North Sea region power system 2) considering investments in onshore and offshore power generation and transmission including the offshore grid.

By performing the intertemporal approach, a step further is taken distinguishing from previous studies that used a myopic approach, like [11] or [12]. The planning horizon plays a key role when modelling investment decisions. Looking ahead reduces suboptimal investments since expected future costs and benefits related to present investments are considered. The planning horizon can deeply affect the investments in generation and transmission since they are considerably linked [13]. Therefore, if suboptimal investments are to be minimised, an intertemporal approach is desired. When performing intertemporal optimisation, the social discount rate used can play a significant role [14]. This paper contributes to the discussion on the time horizon that should be considered when planning the energy system of the North Sea region by performing investment optimisation of the years 2030 and 2050 with an intertemporal approach, which means that by 2030 , information on 2050 is available. The results are compared to a myopic approach, i.e. to a case where by 2030 the information on 2050 is not used.

In the paper, investment decisions in onshore and offshore power generation as well as transmission are endogenized together. In doing so, the paper contributes to a wider discussion which calls for such variables to be decided by the proposed models instead of being exogenously set [15]. Previous studies fixed all generation as well as the onshore transmission [11], or fixed the full onshore system (generation and transmission) [12]. To study different offshore transmission architectures, the effect of two potential offshore transmission developments in the North Sea region are compared in this paper: a project-based and offshore grid approach.

Offshore grid elements like High Voltage Direct Current (HVDC) lines or hubs contain large fixed costs compared to variable ones [16]. For this reason, a Mixed Integer Linear Programming (MILP) approach is preferred over Linear Programming (LP) [17]. In this paper, the offshore HVDC components are modelled with a MILP approach. This approach is similar to [11] and [12].

To achieve the modelling discussed above, the North Sea region is modelled using the Balmorel energy system model [18] to optimise investment decisions and electricity dispatch towards 2050. Uncertainty can have a crucial role when trying to find out the optimal system development. Different profiles for load, wind generation and solar generation can lead to different found-as-optimal investments in generation and transmission. Several studies have developed methods to integrate stochasticity in the investment optimization. For instance, [19] proposes an algorithm based on Bender's decomposition algorithm and Monte Carlo simulations to optimize transmission expansion problems with increasing wind power integration, whereas [20] proposes a method to take both long- and short-term uncertainty into account when optimizing transmission expansion. In this paper, due to the large size of the system studied, a deterministic approach is however utilized, and hence, uncertainty in the input parameters is not considered. 
It is found that when planning the energy system of the North Sea region, an integrated offshore grid configuration planned over a long planning horizon leads to lowest system costs, providing savings of 701 $\mathrm{M} 2012 /$ year in the studied region.

\subsection{Structure of the paper}

The reminder of the paper is structured as follows: In Section 2, the methodology is explained. Section 3 briefly introduces the most important input data. In Section 4 the studied scenarios are described. The results are presented in Section 5. Section 6 provides discussion on our analysis and results, and Section 7 concludes the paper.

\section{METHODOLOGY}

This section describes the modelling methodologies applied in this paper. First, the main tool utilised, i.e. Balmorel, is introduced. Secondly, the investment optimisation method is presented in detail, and then the approach followed to perform a more accurate system operation optimisation. Finally, the CorRES tool used to simulate the Variable Renewable Energy (VRE) generation time series is presented. A flow chart of the overall process followed in this paper is shown in Figure 1.

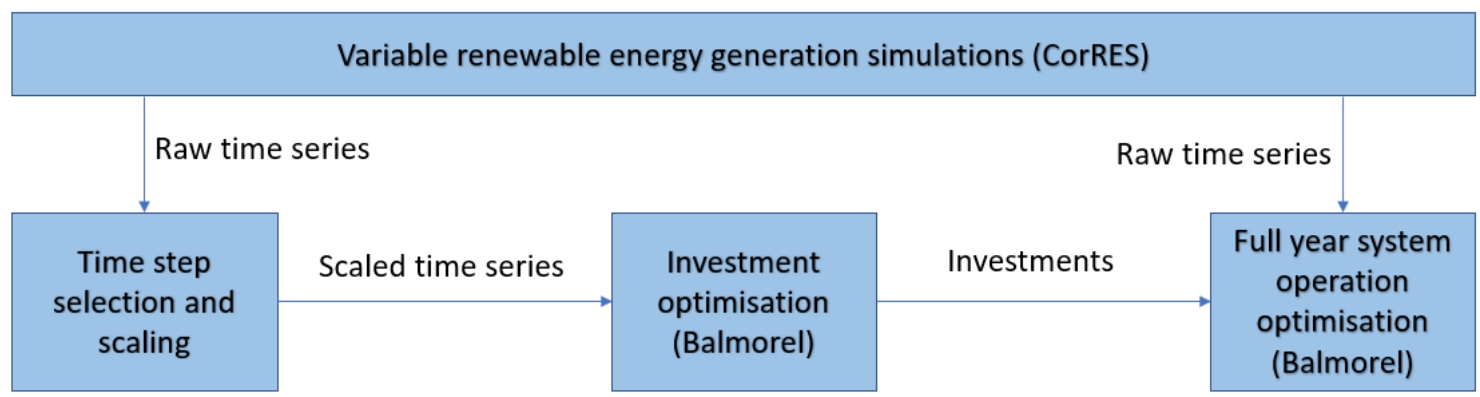

Figure 1. Flow chart of the overall process followed in this paper.

\subsection{Balmorel}

Balmorel is an energy system model that includes the electricity and district heating sectors. It is a linear optimisation tool with optional mixed integer features. It optimises system operation and investments under the assumption of perfect competition [18]. The model is deterministic, which means that uncertainty in the input parameters is not considered in the optimisation. Balmorel has a bottom-up approach and contains a flexible spatial and temporal resolution. Among the different modes of Balmorel, BB4 has been used in this paper, due to the ability to optimise several years simultaneously [18]. This approach is desirable as this paper is focused on planning in the North Sea region. There are three layers of geographical entities to define space in Balmorel: country, region, and area. Electricity trade between regions inside the model is allowed and is subject to the available capacity of the transmission lines. Voltage angles and levels are not considered. A copper plate is assumed inside each region in the model. District heating is modelled without taking grid related issues such as temperature levels or time delays into account. Transmission between district heating areas is not allowed. Further information about Balmorel can be found in [18].

\subsection{Investment optimisation}

\subsubsection{Mathematical formulation of the problem}

The objective of the optimisation is to minimise the System Costs $\left(C^{\text {Sys }}\right)(1)$ allowing for investments in generation technologies and transmission under inelastic demand assumption. This equation calculates:

- $\quad$ the costs of generation investments $\left(C^{\mathrm{g}-\text { inv }}\right)$ for every scenario Year $(Y)$ Area $(A)$ and Generation technology $(G)$,

- $\quad$ the costs of fuel consumption $\left(C^{\text {fuel }}\right)$, Operation and Maintenance $\left(C^{\mathrm{O \& M}}\right)$, and emissions $\left(C^{\mathrm{ems}}\right)$ for every $Y, A, G$, and time step $(T)$,

- $\quad$ the transmission investments costs $\left(C^{\text {trans_inv }}\right)$ for every $Y$ and for every connection between Region $(R)$ and adjacent Region $\left(R^{\prime}\right)$,

- $\quad$ the transmission flow costs ( $\left.C^{\text {trans }}\right)$ for every $Y, T$, between $R$ and $R$ '.

These annual costs are multiplied by the Discount Factor $(D F)$ and Weight $(W)$ of each $Y$. W is a parameter that represents the weight of each scenario year $Y$ included in the simulation, so each $Y$ is treated as an average of a particular time period. $W$ is introduced for the sake of reducing the size of the problem. The interpretation of the $D F$ is explained in section 2.2.

$$
\min C^{S y s}=\sum_{Y} D F_{Y} W_{Y}\left[\begin{array}{c}
\sum_{A, G}\left\{\boldsymbol{C}_{Y, A, G}^{g_{i n v}}+\sum_{T}\left(\boldsymbol{C}_{Y, A, G, T}^{\text {fuel }}+\boldsymbol{C}_{Y, A, G, T}^{O \& M}+\boldsymbol{T}_{Y, A, G, T}^{e m s}\right)\right\}+ \\
\sum_{R, R^{\prime}}\left\{\boldsymbol{C}_{Y, R, R^{\prime}}^{\text {trans }}+\sum_{T} \boldsymbol{C}_{Y, \mathcal{R}, \boldsymbol{R}^{\prime}, T}^{\text {trans }}\right\}
\end{array}\right]
$$


The annualised generation investment cost of a given $G$ invested in $A$ paid in $Y$ is calculated with (2). For every $G$, the cost is obtained by multiplying the specific investment cost of the technology $\left(C^{\mathrm{g} \_ \text {inv }}{ }^{\text {cost }}\right)$, the investment $\left(K^{\text {inv }}\right)$, and the annuity of the investment, which is calculated based on the interest rate and lifetime of the technology. The annuity term is introduced to annualise the capital cost of the technology, so technologies with different lifetimes can be compared [18]. The investment cost is therefore yearly paid during the Lifetime $(L)$ of each generation technology, starting in the investment year $Y^{\prime}$.

$$
C_{Y, A, G}^{g_{i n v}}=C_{Y^{\prime}, A, G}^{g_{-} i n v_{-} \operatorname{cost}} K_{Y^{\prime}, A, G}^{i n v} a_{G} \quad \forall Y, Y^{\prime}, A, G \quad \mid Y<\left(Y^{\prime}+L_{G}\right)
$$

The annualised transmission investment cost for every line connecting $R$ and $R$ ' for each $Y$ of an investment made in the year $Y^{\prime}$ is calculated with (3). For every connection R and R', this cost is obtained by multiplying the specific investment cost of the line ( $\left.C^{\text {trans_inv_cost }}\right)$, the investment $\left(X^{\text {inv }}\right)$, and the annuity of the investment, which is calculated based on the interest rate and lifetime of the transmission line. The annuity applied is the average between the annuities of the two regions connected. The additional 0.5 is to not double count the cost of the line. The annuity term is introduced to annualise the capital cost of the transmission line for the same reason as explained for generation investments.

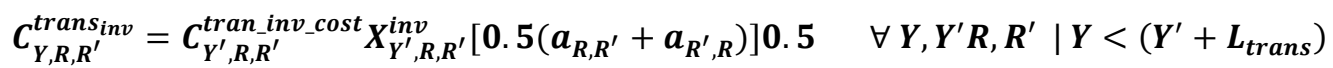

Traditional system operation constraints, such as energy balances, technology constraints, or storage volumes are also part of the optimisation [18]. The energy balance constraints assure that, for each $R$, the sum of the energy production, and net imports is equal to the energy demand plus the transmission losses. Furthermore, generation technology operation constraints are used to represent the limitations and capabilities of every $G$. For example, the maximum production constraints establish that the generation in a given $T$ of a given $G$ has to be lower or equal to the maximum capacity times its availability factor in that $T$. Other types of constraints, including those establishing fuel potentials or the minimum level of hydro reservoir in a given geographical location and temporal dimension, contribute significantly towards a realistic solution [18].

\subsubsection{Intertemporal optimisation}

For an investor, it is important to make investment decisions based not only on the present, but also to take the expectations to the future into account. Hence, when modelling investment decisions, limited foresight could lead to suboptimal investments, which can lead to higher system costs. Therefore, it is relevant to expand the foresight when performing investment optimisation, especially on the energy system context, where investment decisions are made for very long time periods.

Intertemporal optimisation means expanding the foresight, i.e. optimizing several periods at the same time. Under intertemporal optimisation, how much one should value the future relative to the present, i.e. the choice of the Discount Rate $(D R)$, is an important and difficult decision. Much discussion has been going on around the correct value of the $D R$ when performing socio-economic analysis [21]. Thus, it is important to consider the impact of such a parameter in an investment optimisation problem, since it can have a strong influence on the results [14]. In the model, the $D R$ is used to calculate the $D F$, which is then applied in the objective function to weight the cost of future years (1). The annual $D F$ is calculated as

$$
D F_{Y}=(1+D R)^{-\left(Y-Y_{1}\right)} \quad \forall Y
$$

The $D F$ establishes how much nominal savings are required from the future to add an extra cost in the present. If having an extra cost in the present does not add up to at least the same amount of discounted savings in the future, this extra cost will not take place. A $D R$ of 0 would lead to applying equal discounting weight to all the periods in the optimisation, whereas an infinite $D R$ could be considered equivalent as performing "myopic optimisation" or "single period" optimisation, since applying such a $D R$ means that the value of future costs and benefits with respect to the present ones are negligible.

\subsubsection{Mixed Integer Linear Programming}

There is a wide range of possibilities in terms of binary variables that could be applied to model economies of scale, e.g. general integers, partial integers, semi-continuous variables, Special Ordered Sets (SOS) [17]. However, in this paper SOS of type 2 (SOS2) variables will be used as they are generally found to make the branch and bound optimisation process faster [22], and are commonly used for modelling piecewise approximation functions of a unique variable [17], which improves the modelling of economies of scale. Further detailed information about SOS2 variables can be found in [23].

SOS2 variables are used in this paper to implement offshore HVDC component costs as given in [16] in Balmorel. The cost model for the HVDC components is linear; however, it produces non-linear costs per installed capacity, as there are fixed costs for each component. These non-linear costs per installed capacity 
are approximated with piecewise costs linear functions that are used as input relevant for the SOS2 variables in Balmorel. The cost model for a HVDC project is

$$
C_{\mathrm{HVDC}}=B+N+O,
$$

where $B$ denotes branch (line) costs, $N$ node (connection point) costs and $O$ the additional costs of a node built offshore [16]. These components are divided to fixed costs and costs per distance and installed capacity. For the branch,

$$
B=B_{0}+B_{1}+B_{\mathrm{lp}},
$$

where $B_{0}$ is the fixed cost, $B_{1}$ is the length-dependent cost and $B_{\mathrm{lp}}$ is the length- and power-dependent cost. For a node,

$$
N=N_{0}+N_{\mathrm{p}},
$$

where $N_{0}$ is the fixed cost and $N_{\mathrm{p}}$ is the power-dependent cost. When a node is built offshore, the additional costs are modelled according to [16] as

$$
O=O_{0}+O_{\mathrm{p}}
$$

where $O_{0}$ is the fixed additional cost of building an offshore node (offshore hub) and $O_{\mathrm{p}}$ is the powerdependent additional cost.

Depending on the type of project, different cost components are considered. For example, for a radially HVDC connected offshore wind power plant (OWPP), a branch and two nodes are needed (one for the OWPP side and one for the grid side). One of the nodes is offshore, so additional offshore cost is assigned to one node. For a country-to-country HVDC interconnector, two nodes and a branch are needed; however, no additional offshore node cost are added as both nodes are onshore. The protection of HVDC lines, i.e. breakers, is not included in the costs of this technology due to lack of data. More information about the costs can be found in [24].

\subsubsection{Time step selection and scaling of the timeseries}

When optimizing generation and transmission investments together, including MILP of the offshore grid elements, as well as an intertemporal approach, computational time becomes a critical issue. Decreasing the number of time steps reduces computational time. However, the selection of these time steps is not trivial and should aim at accurately representing the full year. This means that the statistical properties of the full year data should be preserved, especially for VRE generation and load. Choosing too optimistic weeks in relation to VRE generation could lead to an underestimation of the required capacity of the energy system. In this paper, the time series used correspond to a unique meteorological year.

Eight weeks spread-over-the-year, taking one every two hours, are found as the convenient amount of time steps to perform the optimisation. The approach utilised to select the time steps is to run different sets of eight weeks spread-over-the-year, taking one every two hours, in the scenario with the least complexity. The average investment results of these sets are defined as the reference, and the set with results closer to the reference is chosen for the optimisation. The selected time series are used in the modelling of all the scenarios to make the results comparable.

In the optimisations, the selected time series are scaled to give a fair representation of the full meteorological year. Seasonal hydro inflow and hourly district heating load profiles are scaled linearly with respect to the average of the full year. This means that, for example, if the weeks selected have less hydro inflow than the average of the year, then the selected time steps will be scaled up. On the other hand, hourly electricity load and VRE generation time series are scaled using probability integral transformations to match the probability distributions of the full year of data. The transformations are applied as follows for a time series $y_{t, \text { fullYear, }}$, which denotes full year of data for a single VRE source or load, e.g. offshore wind generation of western

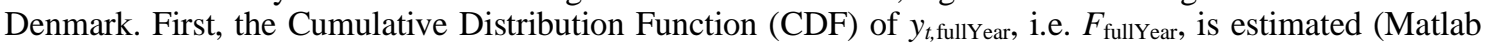
function paretotails [25] was used with an empirical distribution fit covering all the observations). Then, the reduced time step selection is applied and $y_{t \text {,reduced }}$ is obtained; $y_{t \text {,reduced }}$ represents the same VRE generation

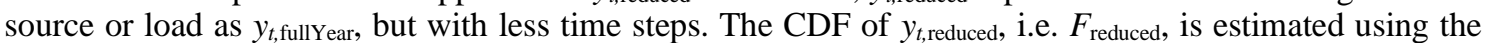
same method as explained above. Following the approach used, e.g. in [26], $y_{t \text {,reduced }}$ is transformed to $y_{t, \text { reduced as }}^{*}$

$$
y_{t, \text { reduced }}^{*}=F_{\text {fullYear }}^{-1}\left(F_{\text {reduced }}\left(y_{t, \text { reduced }}\right)\right) .
$$

$y_{t, \text { reduced }}^{*}$ are the data used in the Balmorel investment optimisation. When applied for all VRE sources and loads, (9) makes the marginal distributions of the reduced time step data follow the same marginal distributions observed in the full year data set. An additional step is taken after applying (9); namely, the

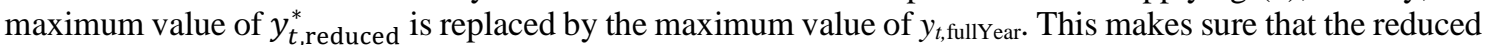
time step data has exactly the same maximum value as observed in the full year data (for each VRE source and load). 


\subsection{System Operation optimisation}

As mentioned in section 2.2.4, performing the investment optimisation with carefully selected time steps can be accurate enough for optimizing investment decisions. However, it is convenient to perform the energy dispatch optimisation with a much higher resolution, in order to get relevant insights about the adequacy of the identified optimal investment solution. The approach selected in this paper is to run the full-year economic dispatch optimisation at an hourly level, using the investment decisions found as optimal from the investment optimisations. To avoid infeasibilities due to underestimation of need for investments, expensive back-up power is introduced. Results from the hourly runs are discussed more in Section 5.3.

\subsection{VRE generation simulations}

VRE generation time series are simulated for Balmorel using the CorRES tool [27]. CorRES is based on reanalysis data obtained from the Weather Research and Forecasting (WRF) model [28], with meteorological downscaling, stochastic fluctuation simulation and conversion from meteorological data to VRE generation time series as described in [27].

For the modelling in CorRES, technical VRE generation parameters, such as wind turbine hub heights, are required to estimate the capacity factors $(\mathrm{CFs})$ of VRE generations in the different analysed areas. These assumptions are described in Section 3.4 for the scenarios analysed in this paper.

In addition to estimating CFs, CorRES can model the spatiotemporal dependencies in VRE generation, as has been demonstrated, e.g. in [29], where wind and solar PV time series were simulated, and [30], where the variability of future residual load was estimated. The modelling provides to Balmorel VRE generation profiles where the correlation structures of wind and solar PV generation, and the correlations between wind and solar PV generation, are modelled.

\section{INPUT DATA}

This section describes the key input data utilised in this paper. For the full input data description, see [24].

\subsection{Geographical scope}

The countries in focus, i.e. countries for which investments in transmission and generation are optimised, are Denmark (DK), Norway (NO), Germany (DE), Great Britain (GB), Netherlands (NL) and Belgium (BE). For the surrounding countries, i.e. Sweden, Finland, Estonia, Latvia, Lithuania, France, and Poland participate in the energy trading, the energy system development is assumed exogenous and similar to [31].

\subsection{Electricity demand, fuel costs and CO2 price development}

In the electricity consumption development scenario, extracted from [31], aggressive energy efficiency policies as well as limited coupling of the different energy sectors are assumed, which leads to an overall stagnating development in the consumption. With respect to fossil fuel prices almost no change with respect to 2014 values is assumed. On the other hand, a considerable increase in the $\mathrm{CO}_{2}$ price is assumed, reaching $136 € 2015 /$ ton by 2050 [31].

\subsection{Exogenous energy system development}

The exogenous transmission grid evolution towards 2030 used in this paper [31] is quite positive. Projects like the Viking Link and the COBRA line are assumed to be realised, and the north to south current congestions problems in Germany are assumed to be reduced considerably.

The development towards 2050 in installed heating and storage capacity for the countries in focus is assumed exogenous and obtained from [31]. For these countries, the electric part of the system is optimised, while linear decommissioning for fossil fuel thermal power plants as well as lifetime expectancy for nuclear power plants are assumed. Decommissioning for existing wind and solar PV capacities is not modelled. For the surrounding countries, energy systems development is taken exogenously from [31].

\subsection{Technology costs and VRE timeseries and potentials}

VRE technology costs are taken mainly from [32]. This source assumes a decrease in future costs of VRE, especially solar PV. The average cost parameter set from [16] is used for offshore HVDC infrastructure in equations (5) to (8). The onshore transmission expansion costs are taken directly from [31]. The wind and solar PV time series are simulated using the CorRES tool as explained in section 2.4, whereas the rest of the time series used in the optimisation are taken from [31]. The assumed VRE technology development for CorRES towards 2050 follows [32], as described in [24]; this ensures that the VRE CFs are aligned with the assumed VRE costs.

The potentials for offshore wind are obtained from a database at DTU Wind Energy (based on [33]); they are further split to nearshore and HVAC, and HVDC connectable potentials, and to hub-connectable potentials in the offshore grid scenario, as shown in [24]. Onshore wind potentials are based on [31]; however, as described in, [24], it was considered that these numbers may be somewhat high, e.g. for GB $(38.4 \mathrm{GW})$, as building significantly more onshore wind can be challenging due to social and political 
opposition. Thus, the results presented in this paper are based on the low onshore wind potential assumption described in [24]. For solar PV, the capacity potentials by 2050 are taken from [34]. Solar PV and onshore wind potentials are divided into three resource grades, as described in [24], to model the expected decrease in VRE CFs as more generation is installed in a region.

\subsection{Variable Renewable Energy and load scaling}

The estimated Probability Distribution Function (PDF) of the original time series, selected time series, and scaled selected time series, are depicted on the left of Figure 2 for an example offshore wind area. On the right, the original and the scaled selected time series of the same area are shown for a selected 50-hour period (standardized generation gets values between 0 and 1, where 1 means generation at installed capacity). The PDFs show that the probability distributions of the scaled selected time series and the original time series are almost identical. The time series plots show that the scaled and the original time series have similar temporal behaviour; this shows that while forcing the CDF in (9), the temporal behaviour remains similar after the transformation. The same holds for spatial dependencies between the different time series (VRE generations and loads), as has been shown, e.g. in [26].
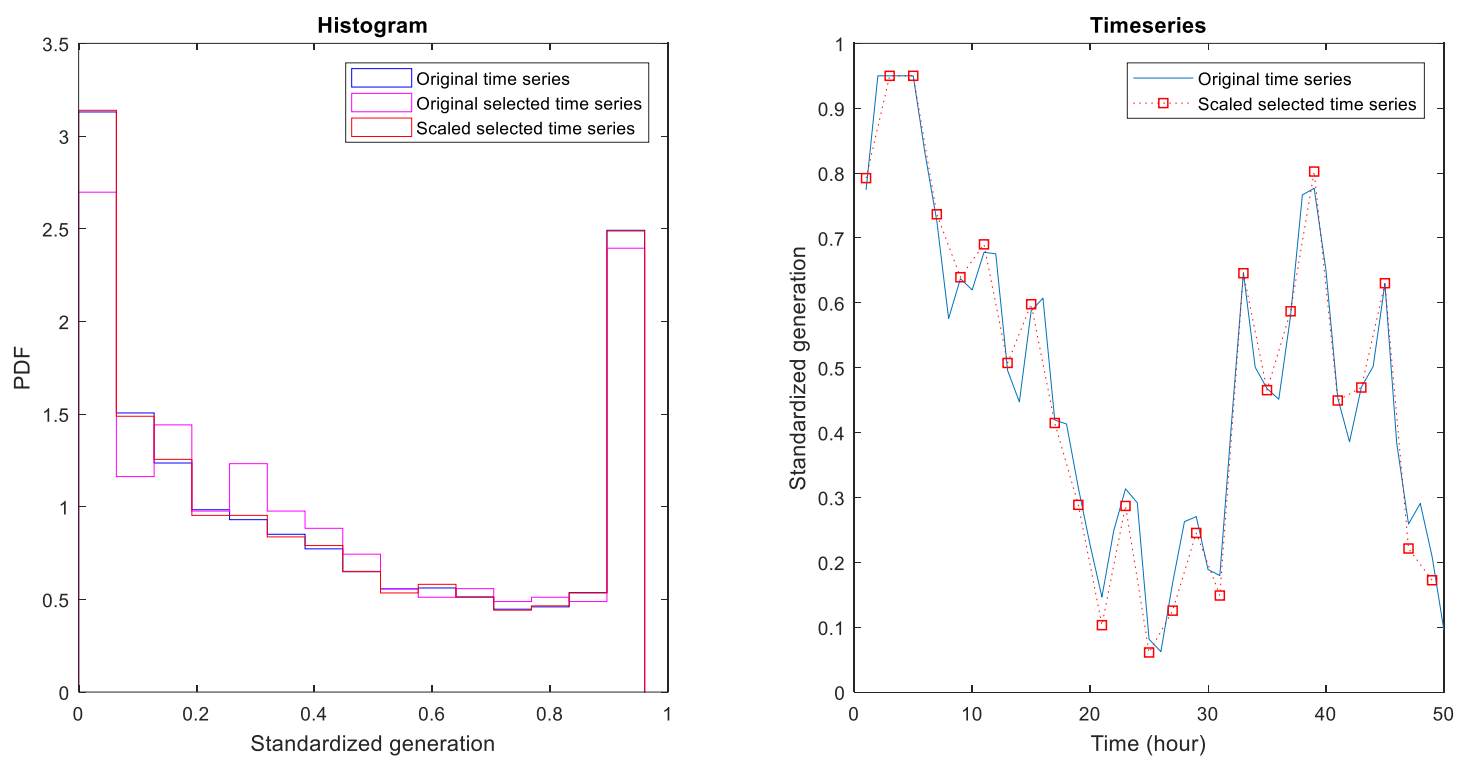

Figure 2. Left: Probability distribution functions (PDFs) of standardized generation of the original, original selected, and scaled selected time series of an example offshore wind area (standardized generation gets values between 0 and 1 , where 1 means generation at installed capacity). Right: Original and scaled selected time series of standardized generation of the same wind offshore area; an example 50-hour period is shown (does not start at the beginning of the year).

\subsection{Social discount rate and technology interest rate assumptions}

The social discount factor (DF) used in the model is $4 \%$, as used in [32]. Interest rate of $8 \%$ is used for generation technologies, as was done in [31]. Interest rate of $4 \%$ is used for transmission lines; a lower rate reflects the fact that transmission investments are generally studied from a social perspective. The interest rates are used in the calculations of the annuity terms of (3) and (4) of Section 2.

\section{SCENARIOS}

In this paper, the investment optimisation of transmission and electricity generation capacities of the North Sea region in the countries in focus has been performed based on the methodology explained in section 2. The generation technologies allowed for investments are wind onshore, wind offshore, solar PV, and several types of thermal condensing power plants (more details can be found in [24]). The studied period of time is 40 years, represented by the snapshot of the scenario years 2030 and 2050, meaning that each of these years has a weight on the objective function of 20 years.

Four different scenarios are defined (Table 1): two different grid architectures under limited and perfect foresight respectively. These scenarios aim at showing the importance of 1) offshore grid structure, and 2) the impact of foresight when modelling investment decisions. The two grid architectures analysed are a project-based and an offshore grid-based. In the project-based case the Offshore Wind Power Plants (OWPP) are radially connected and the countries are connected through country to country (C2C) offshore transmission lines. In the offshore grid case, there are more investment possibilities since, the OWPPs can be either radially connected or hub-connected. Furthermore, besides $\mathrm{C} 2 \mathrm{C}$ transmission lines, hub to hub $(\mathrm{H} 2 \mathrm{H})$ as well as hub to country (H2C) transmission lines are possible [24]. Regarding the foresight, results 
from an intertemporal optimisation are compared to a myopic one. Additionally, a more detailed system operation optimisation has been performed based on the methodology of section 2.3.

\begin{tabular}{|c|c|c|}
\hline Scenario & Foresight approach & Offshore investment possibilities \\
\hline $\begin{array}{c}\text { Project-based }- \\
\text { myopic }\end{array}$ & Myopic & $\begin{array}{c}\text { Radially connected OWPPs. } \\
\text { C2C offshore transmission lines. }\end{array}$ \\
\hline $\begin{array}{c}\text { Offshore grid }- \\
\text { myopic }\end{array}$ & Myopic & $\begin{array}{c}\text { Hub-connected and radially connected OWPPs. } \\
\text { Hubs and C2C, H2H, H2C transmission lines. }\end{array}$ \\
\hline $\begin{array}{c}\text { Project-based }- \\
\text { intertemporal }\end{array}$ & Intertemporal & $\begin{array}{c}\text { Radially connected OWPPs. } \\
\text { C2C offshore transmission lines. }\end{array}$ \\
\hline $\begin{array}{c}\text { Offshore grid - } \\
\text { intertemporal }\end{array}$ & Intertemporal & $\begin{array}{c}\text { Hub-connected and radially connected OWPPs. } \\
\text { Hubs and C2C, H2H, H2C transmission lines. }\end{array}$ \\
\hline
\end{tabular}

Table 1: Summary description of the scenarios.

\section{RESULTS}

This section describes the results obtained in the different scenarios. First, the investment optimisation results are presented, comparing the total system costs for the four scenarios. In the next step the resulting optimal grid architecture and generation development is shown, including the impact of the grid topology and planning horizon on the system development. Finally, the system operation optimisation results are presented.

\subsection{Investment optimisation - System costs}

The total nominal annual system cost difference of the scenarios relative to the simplest scenario, i.e. Projectbased - myopic, is presented in Table 2. In Table 3, these total cost differences of the scenarios are disaggregated into transmission investments costs, generation investments costs, Operation and Maintenance $(\mathrm{O} \& \mathrm{M})$ variable costs, and O\&M fixed costs. Transmission investments include those lines that can be used as interconnectors between regions, therefore radially connected offshore is not part of this group but included in the generation investment group. These cost differences are shown for each of the optimisation years, i.e. 2030 and 2050, and for the average of these two years.

\begin{tabular}{|c|c|c|c|}
\cline { 2 - 4 } \multicolumn{1}{c|}{} & \multicolumn{3}{c|}{ Cost difference with respect to reference (m€2012/year) } \\
\hline Scenario & $\mathbf{2 0 3 0}$ & $\mathbf{2 0 5 0}$ & Average \\
\hline Offshore grid - myopic & -417 & -652 & -534 \\
\hline Project-based - intertemporal & 132 & -592 & -230 \\
\hline Offshore grid - intertemporal & -334 & -1068 & -701 \\
\hline
\end{tabular}

Table 2: Cost difference in the total nominal annual system costs with respect to reference (Project-based - myopic).

\begin{tabular}{|c|c|c|c|c|c|}
\cline { 2 - 6 } \multicolumn{2}{c}{} & \multicolumn{3}{c|}{ Cost difference with respect to reference (m€2012/year) } \\
\hline Scenario & Year & Trans. Invest. & Gen. Invest. & O\&M Var. & O\&M Fixed \\
\hline \multirow{2}{*}{$\begin{array}{c}\text { Offshore grid - } \\
\text { myopic }\end{array}$} & $\mathbf{2 0 3 0}$ & 310 & -399 & -229 & -99 \\
\cline { 2 - 6 } & $\mathbf{2 0 5 0}$ & 631 & -139 & -1085 & -59 \\
\cline { 2 - 6 } & Avg. & 471 & -269 & -657 & -79 \\
\hline \multirow{2}{*}{$\begin{array}{c}\text { Project-based - } \\
\text { intertemporal }\end{array}$} & $\mathbf{2 0 3 0}$ & -84 & -1696 & 2215 & -303 \\
\cline { 2 - 6 } & $\mathbf{2 0 5 0}$ & 116 & -461 & -163 & -83 \\
\hline \multirow{2}{*}{$\begin{array}{c}\text { Offshore grid - } \\
\text { intertemporal }\end{array}$} & $\mathbf{2 0 3 0}$ & 16 & -1078 & 1026 & -193 \\
\cline { 2 - 6 } & $\mathbf{2 0 5 0}$ & 166 & -1680 & 1516 & -336 \\
\hline
\end{tabular}

Table 3: Cost difference in the disaggregated nominal annual system costs with respect to reference (Project-based - myopic).

The results show that the offshore grid case is more cost effective than the project-based case regardless of the planning horizon. Offshore grid - myopic offers savings of $534 \mathrm{~m} € 2012 /$ year compared to Project-based - myopic, and Offshore grid - intertemporal offers savings of $471 \mathrm{~m} € 2012 /$ year with respect to Project-based - intertemporal. This suggests that planning ahead reduces the benefits of building a complicated offshore grid by $63 \mathrm{~m} € 2012 /$ year with respect to a project-based solution. The Offshore grid - myopic and Offshore grid - intertemporal cases require higher investments in interconnections compared to their corresponding Project-based cases. However, they offer considerable savings in generation investments and especially in O\&M variable costs, which compensate the increase in interconnection costs. 
The importance of the level of foresight is further illustrated by the fact that regardless of the grid topology, when taking the future into account, the energy system ends up having a lower average yearly cost. Taking the future into account offers savings of 230 m€2012/year with a project-based topology and 167 m€2012/year with an offshore grid topology. This suggests that when building an offshore grid, the benefits of taking the future into account are decreased $63 \mathrm{~m} € 2012$ year relative to a project-based solution, which makes an offshore grid solution more robust cost-wise than a project-based one. When an intertemporal optimisation is performed, the average annual costs in 2030 increase. This is because the investment decisions made in 2030 are optimal for the full period, but not necessarily for 2030 alone. In this case, some investments decisions wait for 2050, increasing O\&M variable costs by 2030 . However, the extra cost incurre by 2030 is outweighed by the savings in investments obtained by 2050 , leading to scenarios with lower average yearly costs than the respective myopic ones.

The scenario exhibiting the lowest costs is the offshore grid - intertemporal, where the average savings relative to the simplest scenario are found to be $701 \mathrm{m€2} 2012$ year.

\subsection{Investment optimisation - Generation and transmission development}

This subsection shows the optimal generation and transmission development, as well as the impact of the offshore grid investment possibilities and the planning horizon on these.

\subsubsection{Optimal generation and transmission development}

The transmission system and generation development for the found-as-optimal scenario in section 4, i.e. Offshore grid - intertemporal, are shown in Figure 3 and Table 4, respectively.

2030

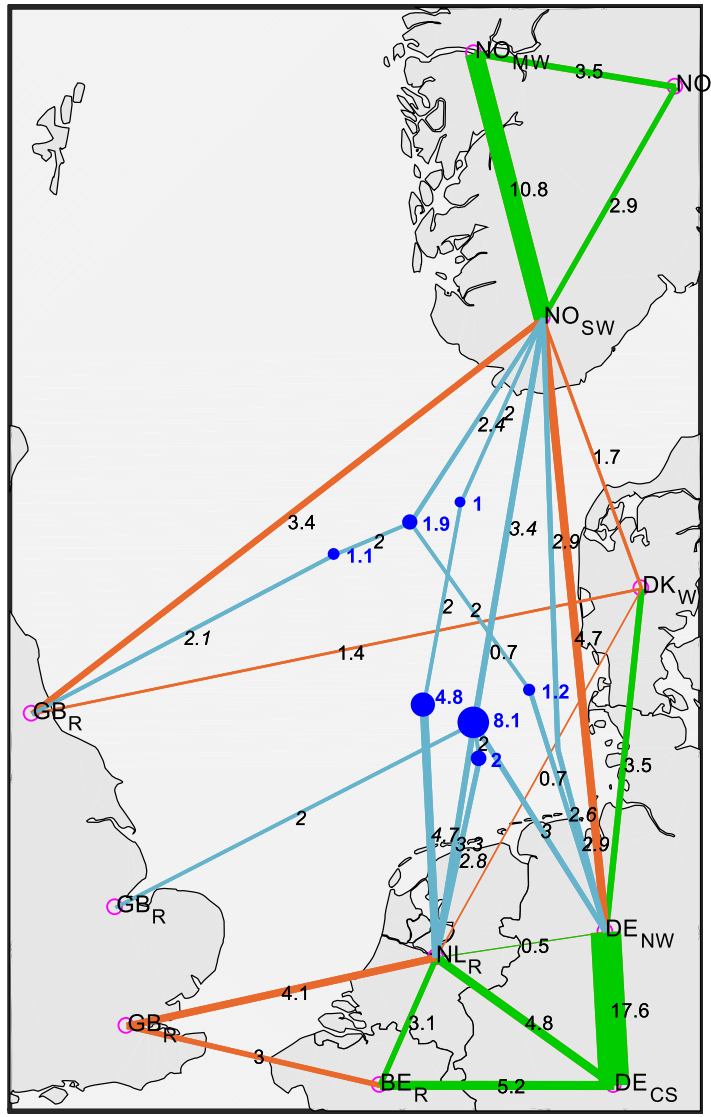

2050

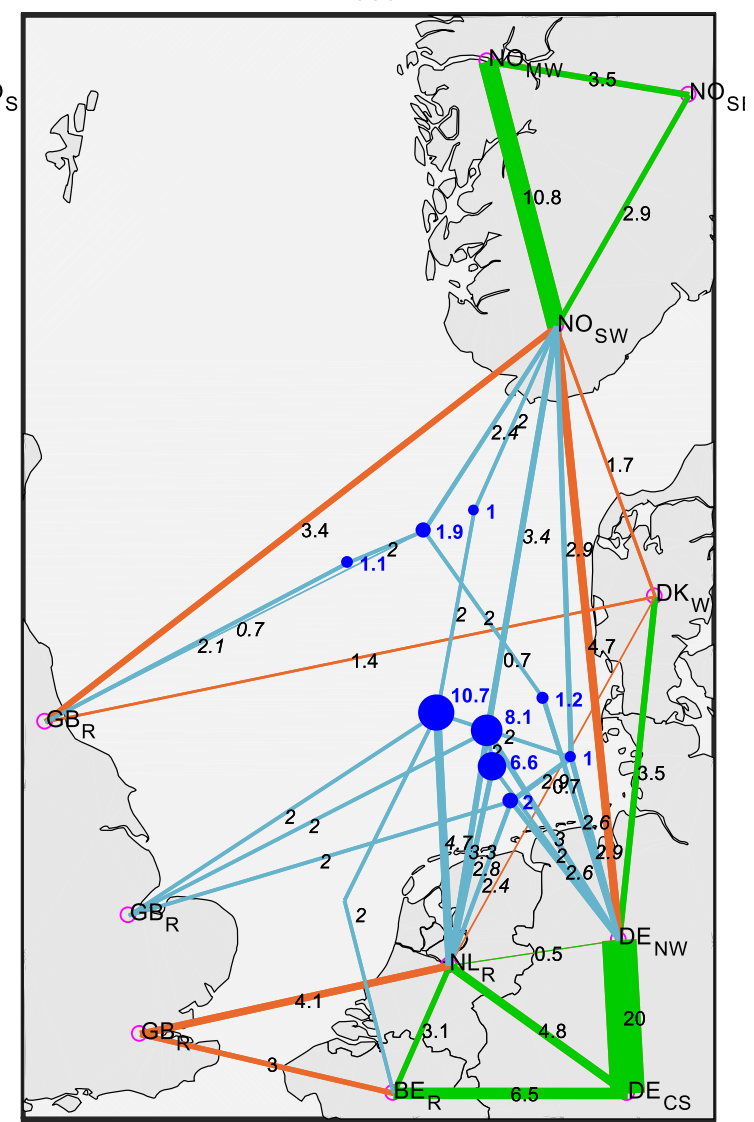

Figure 3. Offshore grid - intertemporal scenario: transmission lines and hubs in 2030 and 2050 (GW). On-land lines in green, C2C offshore lines in orange, lines related to the meshed grid in light blue and hubs in dark blue.

The results show a considerable development of the offshore grid in the North Sea towards 2050. The corridors GB-NO, GB-BE-DE, and DE-NO seem to be key in the future energy system. These corridors are split into direct $\mathrm{C} 2 \mathrm{C}$ and hub-connected lines. The benefit from this architecture is that hub-connected lines can be used for both wind offshore dispatch and $\mathrm{C} 2 \mathrm{C}$ dispatch. The interconnections to NO are especially crucial because the hydro power of this country is used to integrate large shares of VRE in the other countries. The importance of the planning horizon is reflected in the $2.9 \mathrm{GW}$ line built between NO and DE in 2030, which in that year works solely for $\mathrm{C} 2 \mathrm{C}$ dispatch, but in 2050 it is used also for wind offshore dispatch since a hub is built in the middle of the line. 
With respect to the generation capacity development towards 2050, the increase in installed capacity of VRE is remarkable, especially wind offshore, whereas the condensing power is drastically reduced towards 2050. Most of the wind onshore potential is built already by 2030, which reflects that this technology is generally the most profitable. It is also interesting to see that $\mathrm{NO}$ and DE are the countries where the hubs are built; overall, $35 \%$ of total wind offshore capacity is hub-connected by 2050 . However, the energy produced in the windfarms connected to these hubs is not kept for themselves but distributed together with the other countries. This emphasizes the importance of not establishing nationalities when building an offshore grid.

\begin{tabular}{|c|c|c|c|c|c|c|c|c|c|c|c|c|c|}
\hline & \multicolumn{3}{|c|}{ Solar PV } & \multicolumn{3}{c|}{ Offshore wind } \\
\cline { 2 - 11 } & $\mathbf{2 0 2 0}$ & $\mathbf{2 0 3 0}$ & $\mathbf{2 0 5 0}$ & $\mathbf{2 0 2 0}$ & $\mathbf{2 0 3 0}$ & $\mathbf{2 0 5 0}$ & $\mathbf{2 0 2 0}$ & $\mathbf{2 0 3 0}$ & $\mathbf{2 0 5 0}$ & $\mathbf{2 0 2 0}$ & $\mathbf{2 0 3 0}$ & $\mathbf{2 0 5 0}$ \\
\hline BE & 3.4 & 8.6 & 11.8 & $\begin{array}{c}1.6 \\
(0 \%)\end{array}$ & $\begin{array}{c}6.0 \\
(0 \%)\end{array}$ & $\begin{array}{c}6.0 \\
(0 \%)\end{array}$ & 2.3 & 4.4 & 4.4 & 9.7 & 8.4 & 7.1 \\
\hline DE & 52.0 & 78.6 & 98.6 & $\begin{array}{c}7.4 \\
(0 \%)\end{array}$ & $\begin{array}{c}24.6 \\
(69 \%)\end{array}$ & $\begin{array}{c}40.8 \\
(77 \%)\end{array}$ & 49.5 & 57.3 & 62.3 & 35.2 & 26.6 & 13.0 \\
\hline DK & 0.9 & 2.1 & 9.0 & $\begin{array}{c}1.7 \\
(0 \%)\end{array}$ & $\begin{array}{c}6.0 \\
(0 \%)\end{array}$ & $\begin{array}{c}6.9 \\
(0 \%)\end{array}$ & 4.1 & 6.5 & 6.5 & 0.1 & 0.0 & 0.0 \\
\hline GB & 11.5 & 17.9 & 42.6 & $\begin{array}{c}10.5 \\
(0 \%)\end{array}$ & $\begin{array}{c}27.7 \\
(0 \%)\end{array}$ & $\begin{array}{c}33.2 \\
(0 \%)\end{array}$ & 11.9 & 20.0 & 20.0 & 53.1 & 41.2 & 31.2 \\
\hline NL & 1.9 & 12.7 & 12.7 & $\begin{array}{c}1.1 \\
(0 \%)\end{array}$ & $\begin{array}{c}1.1 \\
(0 \%)\end{array}$ & $\begin{array}{c}5.2 \\
(0 \%)\end{array}$ & 4.9 & 4.9 & 4.9 & 28.4 & 17.2 & 3.7 \\
\hline NO & 0.0 & 0.0 & 0.0 & $\begin{array}{c}0.0 \\
(0 \%)\end{array}$ & $\begin{array}{c}4.4 \\
(96 \%)\end{array}$ & $\begin{array}{c}9.6 \\
(44 \%)\end{array}$ & 3.5 & 8.0 & 8.0 & 0.0 & 0.0 & 0.0 \\
\hline Sum & 69.8 & 119.9 & 174.7 & $\begin{array}{c}22.2 \\
(0 \%)\end{array}$ & $\begin{array}{c}69.7 \\
(30 \%)\end{array}$ & $\begin{array}{c}101.7 \\
(35 \%)\end{array}$ & 76.2 & 101.1 & 106.1 & 126.5 & 93.5 & 55.0 \\
\hline
\end{tabular}

Table 4: Offshore grid - intertemporal scenario: installed VRE and thermal condensing capacities (GW).

5.2.2 Impact of offshore grid investment possibilities

The influence of the offshore grid investment possibilities on transmission and generation development towards 2050 in the North Sea when performing an intertemporal optimisation is illustrated in Figure 4 and Table 5, which show the evolution of the transmission and generation development for the Project-based intertemporal scenario, respectively. These results are to be compared to those in section 5.2.1, where the Offshore grid - intertemporal scenario is shown. As mentioned in Section 4, the two grid architecture scenarios differ in the offshore grid investment possibilities.
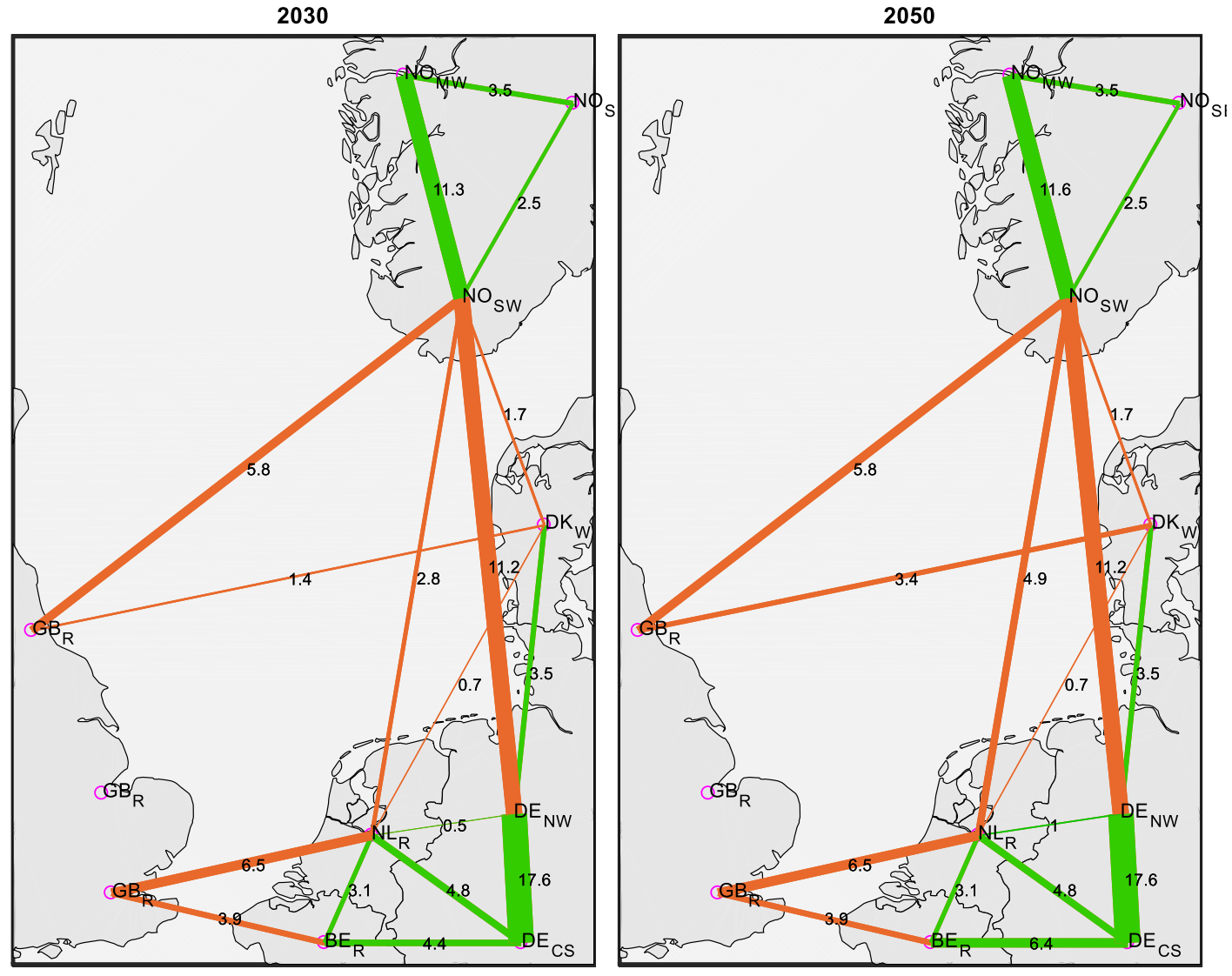

Figure 4. Project-based - intertemporal scenario: transmission lines in 2030 and 2050 (GW). On-land lines in green and C2C offshore lines in orange. 
Regarding the grid development, it can be seen that in the project-based scenario similar levels of high interconnection are achieved by 2050 , however, in the offshore grid topology part of this interconnection is built via hubs.

Comparing the generation investments from the two scenarios, it can be seen that the offshore grid topology ends up with more wind offshore and less wind onshore and solar PV than the project-based solution, and that the offshore grid requires less thermal condensing power. These results suggest that it is more costeffective to provide part of the required flexibility to integrate large shares of renewable energies with an offshore grid transmission development than to build condensing power.

\begin{tabular}{|c|c|c|c|c|c|c|c|c|c|c|c|c|}
\hline & \multicolumn{3}{|c|}{ Solar PV } & \multicolumn{3}{c|}{ Offshore wind } & \multicolumn{3}{c|}{ Onshore wind } & \multicolumn{3}{c|}{ Thermal Condensing } \\
\cline { 2 - 14 } & $\mathbf{2 0 2 0}$ & $\mathbf{2 0 3 0}$ & $\mathbf{2 0 5 0}$ & $\mathbf{2 0 2 0}$ & $\mathbf{2 0 3 0}$ & $\mathbf{2 0 5 0}$ & $\mathbf{2 0 2 0}$ & $\mathbf{2 0 3 0}$ & $\mathbf{2 0 5 0}$ & $\mathbf{2 0 2 0}$ & $\mathbf{2 0 3 0}$ & $\mathbf{2 0 5 0}$ \\
\hline BE & 3.4 & 8.6 & 19.8 & 1.6 & 6.0 & 6.0 & 2.3 & 4.4 & 4.4 & 9.7 & 8.0 & 7.6 \\
\hline DE & 52.0 & 84.3 & 103.7 & 7.4 & 7.8 & 16.2 & 49.5 & 59.0 & 64.0 & 35.2 & 28.8 & 15.2 \\
\hline DK & 0.9 & 2.2 & 9.0 & 1.7 & 6.2 & 8.1 & 4.1 & 6.5 & 6.5 & 0.1 & 0.0 & 0.0 \\
\hline GB & 11.5 & 17.9 & 37.2 & 10.5 & 30.2 & 33.8 & 11.9 & 20.0 & 20.0 & 53.1 & 42.2 & 33.7 \\
\hline NL & 1.9 & 12.7 & 12.7 & 1.1 & 9.2 & 16.3 & 4.9 & 4.9 & 7.5 & 28.4 & 20.0 & 5.5 \\
\hline NO & 0.0 & 0.0 & 0.0 & 0.0 & 4.0 & 11.5 & 3.5 & 11.4 & 11.4 & 0.0 & 0.0 & 0.0 \\
\hline Sum & 69.8 & 125.7 & 182.4 & 22.2 & 63.5 & 91.9 & 76.2 & 106.2 & 113.9 & 126.5 & 99.1 & 62.1 \\
\hline
\end{tabular}

Table 5: Project-based - intertemporal scenario: installed VRE and thermal condensing capacities (GW).

\subsubsection{Impact of planning horizon}

The influence of the planning horizon on transmission and generation development towards 2050 in the North Sea for an offshore grid topology is illustrated in Figure 5 (transmission) and Table 6 (generation). These results correspond to the scenario Offshore grid - myopic, and should be compared to the transmission and generation development of the Offshore grid - intertemporal scenario in section 5.2.1 (Figure 3 and Table 4 respectively).
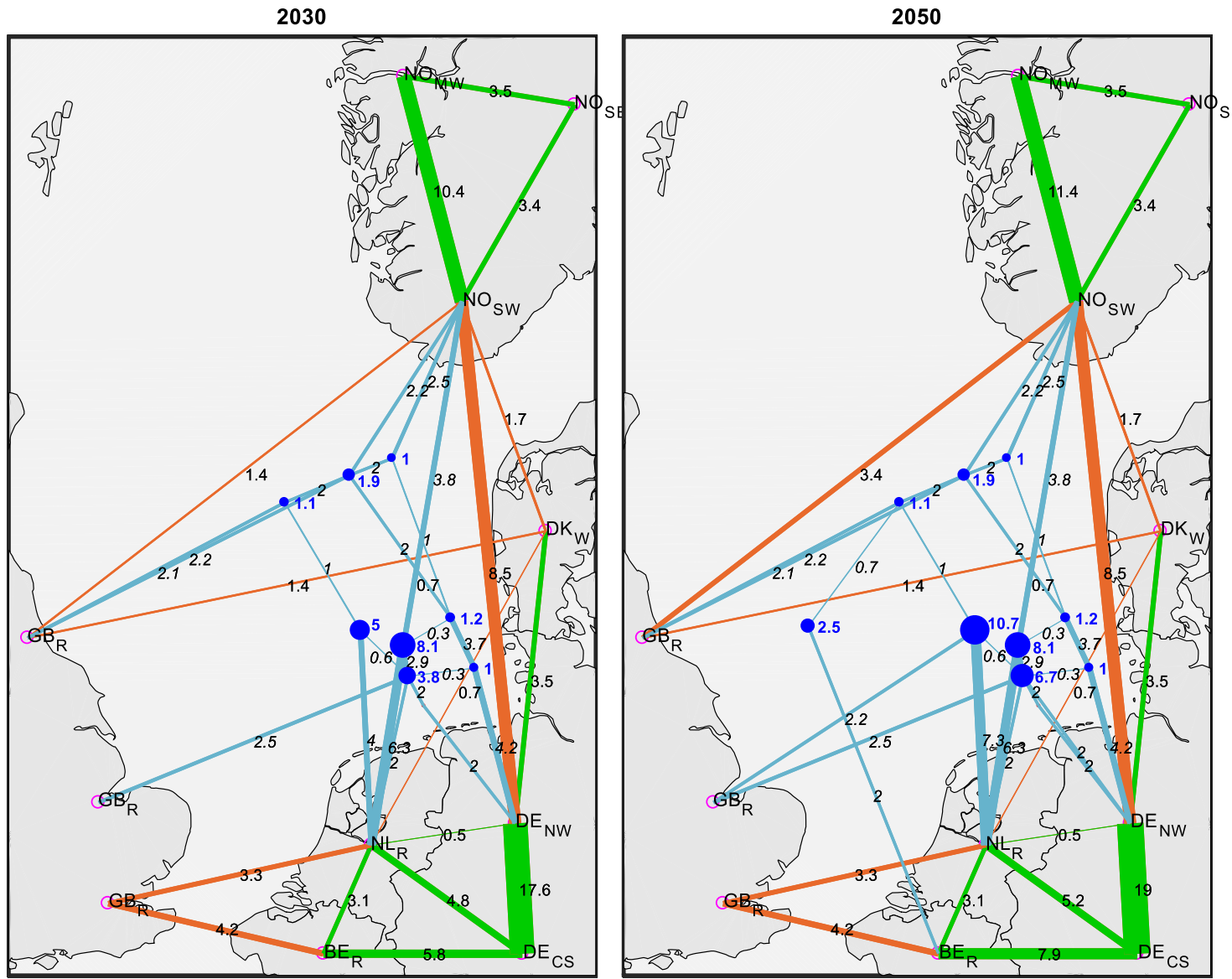

Figure 5. Offshore-grid - myopic scenario: transmission lines in 2030 and 2050 (GW). On-land lines in green and C2C offshore lines in orange.

Making this comparison reveals that independent of the planning horizon the accumulated generation capacity is rather similar in the two scenarios in 2050, whereas in 2030 there are differences between myopic 
and intertemporal optimisation. In the myopic optimisation scenario, the generation capacities by 2030 are generally higher than in the scenario with an intertemporal optimisation, especially Solar PVs. One of the reasons is that in the myopic optimisation the expected price decrease of the investment technologies is not considered. It is found that under intertemporal optimisation it is worth delaying some investments, and thereby using a more expensive available technology in 2030, to benefit from the future price decrease in the long term.

Moreover, since in the myopic approach the further decommissioning taking place by 2050 is not taken into account, the investment results are affected, especially with respect to the distribution of the generation investments. Since transmission and generation investments are considerably linked, the investments in transmission are also influenced for the same reasons, leading to a slightly different configuration of the grid by 2050 due to path dependency with respect to the intertemporal optimisation. The planning effect that was observed in the intertemporal scenario, is not seen in the myopic one, i.e. there is no line built in 2030 that is used for C2C dispatch in 2030, and for C2C and wind dispatch by 2050. Additionally, it is interesting to see that, in the Offshore grid - myopic scenario used in this paper, it is found optimal from a global system perspective to build a hub in GB's waters, and connect it to BE and a hub built in NO's waters. This remarks the importance of international cooperation when dealing with an offshore grid.

\begin{tabular}{|c|c|c|c|c|c|c|c|c|c|c|c|c|c|}
\hline & \multicolumn{3}{|c|}{ Solar PV } & \multicolumn{3}{c|}{ Offshore wind } & \multicolumn{3}{c|}{ Onshore wind } & \multicolumn{3}{c|}{ Thermal Condensing } \\
\cline { 2 - 12 } & $\mathbf{2 0 2 0}$ & $\mathbf{2 0 3 0}$ & $\mathbf{2 0 5 0}$ & $\mathbf{2 0 2 0}$ & $\mathbf{2 0 3 0}$ & $\mathbf{2 0 5 0}$ & $\mathbf{2 0 2 0}$ & $\mathbf{2 0 3 0}$ & $\mathbf{2 0 5 0}$ & $\mathbf{2 0 2 0}$ & $\mathbf{2 0 3 0}$ & $\mathbf{2 0 5 0}$ \\
\hline BE & 3.4 & 8.6 & 11.0 & $\begin{array}{c}1.6 \\
(0 \%)\end{array}$ & $\begin{array}{c}6.0 \\
(0 \%)\end{array}$ & $\begin{array}{c}6.0 \\
(0 \%)\end{array}$ & 2.3 & 4.4 & 4.4 & 9.7 & 9.0 & 7.5 \\
\hline DE & 52.0 & 90.0 & 103.2 & $\begin{array}{c}7.4 \\
(0 \%)\end{array}$ & $\begin{array}{c}27.7 \\
(73 \%)\end{array}$ & $\begin{array}{c}38.8 \\
(75 \%)\end{array}$ & 49.5 & 57.3 & 62.3 & 35.2 & 27.5 & 13.9 \\
\hline DK & 0.9 & 2.5 & 9.0 & $\begin{array}{c}1.7 \\
(0 \%)\end{array}$ & $\begin{array}{c}6.0 \\
(0 \%)\end{array}$ & $\begin{array}{c}7.0 \\
(0 \%)\end{array}$ & 4.1 & 6.5 & 6.5 & 0.1 & 0.0 & 0.0 \\
\hline GB & 11.5 & 17.9 & 39.6 & $\begin{array}{c}10.5 \\
(0 \%)\end{array}$ & $\begin{array}{c}29.4 \\
(0 \%)\end{array}$ & $\begin{array}{c}35.9 \\
(7 \%)\end{array}$ & 11.9 & 20.0 & 20.0 & 53.1 & 40.3 & 30.2 \\
\hline NL & 1.9 & 12.7 & 12.7 & $\begin{array}{c}1.1 \\
(0 \%)\end{array}$ & $\begin{array}{c}1.1 \\
(0 \%)\end{array}$ & $\begin{array}{c}2.9 \\
(0 \%)\end{array}$ & 4.9 & 4.9 & 4.9 & 28.4 & 15.9 & 3.6 \\
\hline NO & 0.0 & 0.0 & 0.0 & $\begin{array}{c}0.0 \\
(0 \%)\end{array}$ & $\begin{array}{c}4.4 \\
(96 \%)\end{array}$ & $\begin{array}{c}11.0 \\
(38 \%)\end{array}$ & 3.5 & 8.4 & 8.4 & 0.0 & 0.0 & 0.0 \\
\hline Sum & 69.8 & 131.7 & 175.6 & $\begin{array}{c}22.2 \\
(0 \%)\end{array}$ & $\begin{array}{c}74.5 \\
(33 \%)\end{array}$ & $\begin{array}{c}101.6 \\
(35 \%)\end{array}$ & 76.2 & 101.5 & 106.5 & 126.5 & 92.6 & 55.3 \\
\hline
\end{tabular}

Table 6: Offshore grid - myopic scenario: installed VRE and thermal condensing capacities (GW).

\subsection{System operation optimisation}

This subsection provides insight on the impact of the time selection on the results and on the electricity generation per fuel for the most relevant scenarios.

\subsubsection{Optimality of time step selection}

The influence of the time step used on the annual aggregated electricity production per fuel in the North Sea region for the Offshore grid - intertemporal scenario is depicted in Table 7. The simulations shown compare the results of the scenario used for the investment optimisation, which contained only the selected time series, and the full year system operation optimisation, with exogenous investments from the selected weeks run plus expensive back-up power. The comparison reveals that the difference in TWh per fuel is not significant. Additionally, the utilization of back-up power is very small compared to the total electricity production. Therefore, it can be concluded that the selected weeks used are representative enough of the full year energywise.

\begin{tabular}{|c|c|c|c|c|c|c|c|c|c|c|}
\hline Year & Simulation & WIND-OFF & WIND-ONS & SUN & WATER & BIOFUEL & NUCLEAR & FOSSIL & BACK-UP & SUM \\
\hline $\begin{array}{c}\text { Investment } \\
\text { Optimisation } \\
\text { (selected time series) }\end{array}$ & 305.1 & 249.2 & 119.2 & 168.2 & 65.6 & 72.4 & 228.9 & 0.0 & 1208.4 \\
\hline $\begin{array}{c}\text { System Operation } \\
\text { (full year) }\end{array}$ & 306.4 & 249.1 & 119.0 & 168.6 & 66.5 & 73.7 & 210.2 & 0.1 & 1193.6 \\
\hline $\mathbf{2 0 5 0}$ & $\begin{array}{c}\text { Investment } \\
\text { Optimisation } \\
\text { (selected time series) }\end{array}$ & 427.5 & 252.8 & 174.9 & 177.4 & 23.3 & 15.4 & 152.1 & 0.0 & 1223.4 \\
\hline $\begin{array}{c}\text { System Operation } \\
\text { (full year) }\end{array}$ & 432.1 & 254.5 & 174.5 & 178.8 & 24.3 & 17.4 & 122.5 & 0.5 & 1204.7 \\
\hline
\end{tabular}

Table 7: Aggregated yearly electricity generation by fuel for the Offshore grid - intertemporal scenario (TWh/year). Full year versus selected time series. 


\subsubsection{Electricity dispatch}

The aggregated yearly electricity generation by fuel, year and selected scenario are illustrated in Table 8 . The penetration of VRE energy towards 2050 is remarkable in any of the scenarios, at the expense of fossil fuels. In the Offshore grid - intertemporal scenario, just the share of production of wind and solar PV together goes from $28 \%$ in 2020, to 57\% in 2030, and to $71 \%$ in 2050. The Project-based - intertemporal scenario has slightly lower shares and TWhs of VRE; the largest difference is that offshore wind generation is higher with an offshore grid topology, at the expense of decreasing the contribution from wind onshore and solar PV. This effect is stronger in 2050. These results suggest that, rather than affecting the penetration of VRE energy, the grid topology will have a larger influence on the relative contribution of each VRE technology.

On the other hand, by 2050 the TWhs generated with the different energy sources are almost identical in the Offshore grid - myopic and Offshore grid - intertemporal scenarios. However, the contribution of VRE in the Offshore grid - intertemporal scenario by 2030 is smaller. As explained in detail in section 5.2.3, this is a result of delayed investments in VRE. This suggests that, rather than affecting the penetration of VRE in the long term, the major impact from building the offshore grid not taking the expected future into account is likely to be economical, as shown in section 5.1.

In the Offshore grid - intertemporal scenario, 62\% of the fossil TWhs are produced with CHP plants in 2050. It needs to be noted that the development of the heating side was not optimized, and therefore the use of CHP plants was required to provide for the heating needs.

\begin{tabular}{|c|c|c|c|c|c|c|c|c|c|c|}
\hline Year & Scenario & WIND-OFF & WIND-ONS & SUN & WATER & BIOFUEL & NUCLEAR & FOSSIL & BACK-UP & SUM \\
\hline 2020 & Starting point & 81.5 & 185.9 & 68.1 & 169.1 & 43.0 & 181.8 & 469.5 & 0.0 & 1198.9 \\
\hline \multirow{3}{*}{2030} & $\begin{array}{l}\text { Offshore grid - } \\
\text { myopic }\end{array}$ & 327.3 & 249.4 & 130.3 & 168.7 & 64.6 & 71.5 & 195.0 & 0.1 & 1207.0 \\
\hline & $\begin{array}{l}\text { Project-based - } \\
\text { intertemporal }\end{array}$ & 273.9 & 259.8 & 124.5 & 168.5 & 67.1 & 74.7 & 218.9 & 0.1 & 1187.7 \\
\hline & $\begin{array}{l}\text { Offshore grid - } \\
\text { intertemporal }\end{array}$ & 306.4 & 249.1 & 119.0 & 168.6 & 66.5 & 73.7 & 210.2 & 0.1 & 1193.6 \\
\hline \multirow{3}{*}{2050} & $\begin{array}{l}\text { Offshore grid - } \\
\text { myopic }\end{array}$ & 430.8 & 255.5 & 174.8 & 178.8 & 24.3 & 17.4 & 121.4 & 0.5 & 1203.4 \\
\hline & $\begin{array}{l}\text { Project-based - } \\
\text { intertemporal }\end{array}$ & 385.0 & 272.8 & 182.0 & 178.7 & 24.8 & 18.1 & 130.1 & 0.5 & 1192.1 \\
\hline & $\begin{array}{l}\text { Offshore grid - } \\
\text { intertemporal }\end{array}$ & 432.1 & 254.5 & 174.5 & 178.8 & 24.3 & 17.4 & 122.5 & 0.5 & 1204.7 \\
\hline
\end{tabular}

Table 8: Aggregated yearly electricity generation by fuel, year and scenario (TWh/year).

\section{Discussion}

Even though the results obtained in this paper provide significant insight of the scenarios, they are subjective to the modelling assumptions. The major limitations of these will be analysed in this section.

Electricity consumption is assumed almost constant because of using the scenarios from [31], where the coupling of the various energy sectors was quite limited and strong energy efficiency measures were considered. The future development is expected to be quite the opposite, i.e. increasing the coupling between the electricity sector and the rest of the energy system. This coupling can increase the load considerably, making transmission investment, as well as taking the expected future into account, even more important. Similar to sector coupling, adding storages as investment possibilities can be a game changer, since they are in direct competition with transmission. The importance of this competition is reflected in the results of [35], which performed an investment optimisation over a full year in the European energy system. Sector coupling will be modelled in future research.

A foresight of 40 years aggregated into two snapshot years might be controversial, since predicting the development of costs and policies is already very complex in the short term. However, it has been shown that not taking the future into account leads to suboptimal investments decisions. Therefore, the definition of long-term clear goals, e.g. reduction of $\mathrm{CO} 2$ emissions which might result in high $\mathrm{CO} 2$ prices, is important to plan the future energy system properly. Foresight up to 50 years is not unusual in energy system analysis [36], and in particular when dealing with capital intensive investments such as transmission grid long time horizons are important [37].

Furthermore, performing investment optimisation with annualised investment costs, aggregated years, and social discount rates is a complex matter. Annualising is a consequence of technologies having different lifetimes and not being able to use infinite foresight due to computational limitation. By annualising, the real benefits and costs of the technologies will not be fully represented. This problem is increased when aggregating years. On the other hand, when applying social discount rates higher than zero the results are biased towards investments that have reduced costs at the beginning of their lifetime, and high towards the end. This is because future costs will have a very low weight in the objective function due to discounting. Nevertheless, these limitations are simply part of the optimisation itself and their impact can only be reduced when higher computational power is available. 
The protection of HVDC lines, i.e. breakers, is not included in the costs of this technology due to lack of data. Nevertheless, the system value of transmission lines was demonstrated in [24], where a sensitivity analysis doubling the costs of the lines was performed, and still, although less, strong transmission reinforcement took place.

In this paper, one meteorological year is used in the optimisation. As VRE plays such an important role in these scenarios, considering different weather conditions to test the system reliability seems reasonable.

The wind onshore potentials behind these analyses reflect a pessimistic view on social acceptance towards this technology (the lower of the onshore wind potential scenarios introduced in [24] was used in this paper). This has a strong impact on the results, since wind onshore is one of the most attractive technologies from a pure economic point of view [32]. To better assess the onshore wind potentials, future research should be relying on modelling of social acceptance. Modelling of social acceptance costs has recently been carried out by [38]. However, to our knowledge the existing analyses on future transmission grids do not include endogenous social acceptance of onshore wind.

Even though expanding the transmission grid seems to be optimal, and particularly in an offshore grid configuration with hub connections, it seems that not all the countries/agents will benefit equally. Some of them might even lose from this expansion, which calls for considerable international cooperation; see for instance [9]. An example of international cooperation to build hub-connected wind farms has recently been realized with the Kriegers Flak project in the Baltic Sea. These aspects will be considered in future research. On-land transmission expansion acceptance is another important matter to tackle, since our results find a considerable expansion of the on-land grid.

The present section presented some of the most important assumptions behind our analysis. Despite the limitations to the analysis, the following conclusions are found valid.

\section{CONCLUSIONS}

This paper has investigated the optimal development of the energy system in terms of generation as well as transmission in the North Sea region and studied the importance of the planning horizon. It is found that when planning the energy system of the North Sea region, an integrated offshore grid configuration planned over a long planning horizon leads to cost minimization, providing considerable savings in the studied region. The grid topology is not likely to influence the overall level of VRE penetration, although it will affect the contribution of each VRE type and the system costs. An integrated offshore grid is expected to increase offshore wind investments compared to a project-based approach.

Rather than affecting the overall penetration of VRE towards 2050, developing an offshore grid without taking the future into account is likely to lead to a more expensive energy system. Furthermore, it is found that running a system with high share of VRE is realistic and cost-efficient. However, a system with large shares of VRE requires significant flexibility. Our study shows that a large share of the flexibility required for this integration could come from reinforcing the transmission grid.

\section{ACKNOWLEDGMENT}

This paper is a part of NSON-DK and Flex4RES projects funded by the Danish Energy Agency, EUDP (grant 64018-0032; previously ForskEL) and Nordic Energy Research (grant 76084), respectively.

\section{REFERENCES}

[1] European commission, (2018) https://ec.europa.eu/energy/en/topics/energy-strategy-and-energy-union (accessed Apr 2018)

[2] D. Gately, (1974). "Sharing the Gains from Regional Cooperation: A Game Theoretic Application to Planning Investment in Electric Power." International Economic Review, vol. 15, no. 1, pp. 195-208. https://www.jstor.org/stable/2526099

[3] H. Bessembinder \& M. L. Lemmon, (2006). "Gains from Trade under Uncertainty: The Case of Electric Power Markets". The Journal of Business, 79(4), pp. 1755-1782. https://www.jstor.org/stable/10.1086/503647

[4] D. Newbery, G. Strbac, \& I. Viehoff, (2016). "The benefits of integrating European electricity markets". Energy Policy, 17 , Volume 94, pp. 253-263. https://doi.org/10.1016/j.enpol.2016.03.047

[5] P. Ringler, D. Keles \& W. Fichtner, (2017). "How to benefit from a common European electricity market design". Energy Policy, 1 2, Volume 101, pp. 629-643. https://doi.org/10.1016/j.enpol.2016.11.011

[6] European Commission - DG for Energy, (2011). "Energy Infrastructure Priorities for 2020 and beyond - A Blueprint for an Integrated European $\quad$ Energy Network," Available: https://ec.europa.eu/energy /sites/ener/files/documents/2011_energy_infrastructure_en.pdf.

[7] J.D. Decker et al., (2011). "Offshore Electricity Grid Infrastructure in Europe", Available: https://ec.europa.eu/energy/intelligent/projects/sites/ieeprojects/files/projects/documents/offshoregrid_offshore_electricity_grid_infrastructure_in_europe_en.pdf

[8] NSCOGI, (2012). "Working - Group 1 - Grid Configuration", Available: http://www.benelux.int/files/1414/0923/4478/North_Seas Grid_Study.pdf.

[9] I. Konstantelos et al., (2017). "Integrated North Sea grids: The costs, the benefits and their distribution between countries". Energy Policy, vol 101, pp. 28-41. https://doi.org/10.1016/j.enpol.2016.11.024

[10] I. Konstantelos, R. Moreno and G. Strbac, (2017). "Coordination and uncertainty in strategic network investment: Case on the North Seas Grid". Energy Economics, vol. 64, pp. 131-148. https://doi.org/10.1016/j.eneco.2017.03.022

[11] J. G. Dedecca, R. A. Hakvoort, P. M. Herder, (2017), "Transmission expansion simulation for the European Northern Seas offshore grid", Energy, vol 125, pp. 805-824. https://doi.org/10.1016/j.energy.2017.02.111 
[12] J. G. Dedecca et al., (2018). "Expansion planning of the North Sea offshore grid: Simulation of integrated governance constraints", Energy Economics, vol 72, pp. 376-392. https://doi.org/10.1016/j.eneco.2018.04.037

[13] D. Pozo, J. Contreras, E. Sauma, (2013). "If you build it, he will come: Anticipative power transmission planning". Energy economics, vol 36, pp. 135-146. https://doi.org/10.1016/j.eneco.2012.12.007

[14] D. García-Gusano et al., (2016), "The role of the discount rates in energy systems optimisation models". Renewable and Sustainable Energy Reviews, vol 59, pp. 56-72. https://doi.org/10.1016/j.rser.2015.12.359

[15] J. G. Dedecca and R. A. Hakvoort, (2016). "A review of the North Seas offshore grid modeling: Current and future research". Renewable and Sustainable Energy Reviews, vol 60, pp. 129-143. https://doi.org/10.1016/j.rser.2016.01.112

[16] P. Härtel. T. K. Vrana, T. Hennig, M. von Bonin, E. J. Wiggelinkhuizen and F. D.J. Nieuwenhout, (2017). "Review of investment model cost parameters for VSC HVDC transmission infrastructure”, Electric Power Systems Research, vol. 151, pp. 419-431. https://doi.org/10.1016/j.epsr.2017.06.008

[17] C. Guéret, C. Prins and M. Sevaux, (2000). "Programmation linéaire". Ed. Eyrolles

[18] F. Wiese et al., (2018). "Balmorel open source energy system model." Energy Strategy Reviews, vol 20, pp. 26-34. https://doi.org/10.1016/j.esr.2018.01.003

[19] G. A. Orfanos, P. S. Georgilakis, (2013). "Transmission expansion Planning of Systems With Increasing Wind Power Integration". IEEE transactions on power systems, 28 (2), 1355-1362. DOI: 10.1109/TPWRS.2012.2214242

[20] X. Zhang, A. J. Conejo, (2018). "Candidate line selection for transmission expansion planning considering long- and short-term uncertainty". International journal of electrical power \& energy systems. Vol. 100, pp. 320-330. https://doi.org/10.1016/j.ijepes.2018.02.024

[21] S. Cruz and M. J. Muñoz, (2005). "Some considerations on the social discount rate". Environmental Science \& Policy, vol 4, issue 4, pp. 343-355. https://doi.org/10.1016/j.envsci.2005.04.003

[22] E. M. L. Beale and J. A. Tomlin, (1970). "Special Facilities in a General Mathematical Programming System for Nonconvex Problems Using Ordered Sets of Variables". In Proc. 5th IFORS Conference, Tavistock. https://www.researchgate.net/profile/John Tomlin/publication/313166553 Special facilities in a general_mathematical_pro gramming system for nonconvex problems using ordered sets of variables/links/5417118a0cf203f155ad3b6f/Specialfacilities-in-a-general-mathematical-programming-system-for-nonconvex-problems-using-ordered-sets-of-variables.pdf

[23] E. M. L. Beale and J. J. H. Forrest, (1976). "Global optimization using special ordered sets". Mathematical Programming, vol 10(1), pp. 52-69. https://doi.org/10.1007/BF01580653

[24] M. Koivisto, J. Gea-Bermúdez, (2018), "NSON-DK energy system scenarios - Edition 2", DTU Wind Energy, available at: http://orbit.dtu.dk/files/160234729/NSON_DK_WP2_D2.1.Ed2_FINAL.pdf (accessed Nov 2018).

[25] MathWorks, "paretotails", description available online at: https://se.mathworks.com/help/stats/paretotails.html (accessed on 14 March 2019).

[26] M. Koivisto, J. Seppänen, I. Mellin, J. Ekström, R. Millar, I. Mammarella, M. Komppula, M. Lehtonen, "Wind Speed Modeling Using a Vector Autoregressive Process with a Time-dependent Intercept Term”, International Journal of Electrical Power and Energy Systems, vol. 77, pp. 91-99, May 2016.

[27] M. Koivisto, K. Das, F. Guo, P. Sørensen, E. Nuño, N. Cutululis and P. Maule, (2018). "Using time series simulation tool for assessing the effects of variable renewable energy generation on power and energy systems", WIREs Energy and Environment. https://doi.org/10.1002/wene.329

[28] W. Skamarock, J. Klemp, J. Dudhia, D. Gill, D. Barker, M. Duda, X. Huang, W. Wang and J. Powers, "Description of the advanced research WRF version 3," Boulder, Colorado, USA, 2008.

[29] E. Nuño, P. Maule, A. Hahmann, N. Cutululis, P. Sørensen and I. Karagali, "Simulation of transcontinental wind and solar PV generation time series", Renewable Energy, vol. 118, pp. 425-436, April 2018.

[30] M. Koivisto, P. Maule, E. Nuño, P. Sørensen, N. Cutululis, "Statistical Analysis of Offshore Wind and other VRE Generation to Estimate the Variability in Future Residual Load", Journal of Physics: Conference Series, vol. 1104, no. 1, 012011, 2018

[31] NORDEN and IEA, (2016), "Nordic Energy Technology Perspectives 2016":http://www.nordicenergy.org/project/nordicenergy-technology-perspectives/ (accessed April 2018)

[32] Danish Energy Agency's Technology Catalogue: https://ens.dk/service/fremskrivninger-analyser-modeller/teknologikataloger (accessed on July 2017)

[33] $4 \mathrm{C}$ offshore wind farm database: http://www.4coffshore.com/ windfarms/ (accessed June 2017)

[34] P. Nahmmacher, E. Schmid and Brigitte Knopf, "Documentation of LIMES-EU - A long-term electricity system model for Europe". Available at: https://www.pik-potsdam.de/research/sustainablesolutions/models/limes/DocumentationLIMESEU 2014.pdf (accessed 19 June 2018)

[35] T. Brown, D. Schlachtberger, A. Kies, S. Schramm, M. Greiner, (2018). "Synergies of sector coupling and transmission reinforcement in a cost-optimised, highly renewable European energy system". Energy, vol 160, pp. 720-739. https://doi.org/10.1016/j.energy.2018.06.222

[36] K. B. Karlsson, S. Petrovic, and R. Næraa, (2016). "Heat supply planning for the ecological housing community Munksøgård". Energy, vol 115(3), pp. 1733-1747. DOI: 10.1016/j.energy.2016.08.064

[37] B. Solano-Rodríguez, A. R. Pizarro Alonso, K. Vaillancourt, and C. Martin-del-Campo, (2018). "Mexico's Transition to a NetZero Emissions Energy System: Near Term Implications of Long Term Stringent Climate Targets". Lecture Notes in Energy (Print), 64, 315-331. https://doi.org/10.1007/978-3-319-74424-7 19

[38] P. Hevia-Koch, H. K. Jacobsen, (2019). "Comparing offshore and onshore wind development considering acceptance costs". Energy Policy, vol 125, pp. 9-19. https://doi.org/10.1016/j.enpol.2018.10.019 